\title{
VARIAÇÃO NO USO DO INFINITIVO PESSOAL
}

\author{
Edair Gorski
}

RESUMO: This paper investigates the variable use of the infinitive in oral Brazilian Portuguese considering both the verb morphology and the formal representation of the subject. The analysis of sociolinguistic interviews shows that the speakers prefer both the non-finite verb form of the infinitive (92\%) and no subject expressed (71\%). These results display a tendency for a regularization of the infinitive as an impersonal form. Empirical results also point out a correlation between finite verb form and formal representation of the subject, which are highly marked constructions. The independent variables subject coreferentiality, semantic (in)determination of the subject and syntactic coding of the clause are statistically significant for the expression of the subject.

$\boldsymbol{P A L A V R A S - C H A V E}$ : infinitivo pessoal, variação lingüística, flexão, sujeito, fala, correferencialidade

\section{INTRODUÇÃO}

A questão do infinitivo pessoal - fenômeno que particulariza o português entre as línguas românicas - e impessoal constitui-se em tema controvertido entre os estudiosos do nosso idioma. Um dos pontos de controvérsia é de ordem conceitual e terminológica. Neste aspecto, o que se verifica é um tratamento que ora se restringe ao plano morfológico da flexão número-pessoal, ora abarca também o nível sintático relativo a presença ou não de sujeito. Camara Jr., por exemplo, utiliza a denominação 'infinitivo pessoal' para designar morfologicamente o infinitivo provido de desinências pessoais, observando em nota que "alguns gramáticos modernos têm impugnado o nome sob a alegação de que 'pessoal' equivale a 'com sujeito' (...)"(1985, p.139). Said Ali fala indistintamente em 'infinitivo pessoal ou flexionado', e 'impessoal ou sem flexão' (assinalando que a N.G.B. prefere a denominação alternativa) (1964, p.175), e

Edair Gorski é professora da Universidade Federal de Santa Catarina. 
admite que "infinitivo sem sujeito é o mesmo que infinitivo sem flexão" (1930, apud ROCHA LIMA, 1972, p.382). Cunha \& Cintra, por sua vez, nos planos sintático e morfológico, consideram como impessoal "o infinitivo que não tem sujeito, porque não se refere a uma pessoa gramatical" e como pessoal "o que tem sujeito próprio e pode ou não flexionar-se" (1985, p.473) (grifo nosso). Decorre daí que a variação no uso do infinitivo pessoal pode ser duplamente tratada: em seu aspecto flexional e no que se refere à existência ou não de sujeito próprio. Esta é a perspectiva adotada neste trabalho.

Outro ponto problemático diz respeito ao emprego do infinitivo, justificado pelos gramáticos, muitas vezes, por razões estilísticas. Cunha \& Cintra chegam a afirmar que os escritores nunca se pautaram "por exclusivas razões de lógica gramatical, mas se viram sempre, no ato da escolha, influenciados por ponderáveis motivos de ordem estilística, tais como o ritmo da frase, a ênfase do enunciado, a clareza da expressão"(op. cit.). Said Ali já apontava que "a escolha da forma infinitiva depende de cogitarmos somente da ação ou do intuito ou necessidade de pormos em evidência o agente do verbo"(op.cit., p. 180). Mais recentemente, Perini chama a atenção para o caráter marginal do infinitivo flexionado dentro da sintaxe do português, afirmando que seu uso vem se reduzindo e que o falante não possui intuições seguras a respeito das condições de sua ocorrência (1996, p. 205). Parece evidente que o assunto carece de um tratamento empírico que possa trazer luzes para uma abordagem mais sistemática do fenômeno.

A despeito do caráter controvertido que cerca o infinitivo em português, a gramática normativa elenca algumas situações de uso, que podem ser resumidas como segue. Usa-se a forma não flexionada, quando: a) o infinitivo é impessoal (não se refere a nenhum sujeito); b) tem valor imperativo; c) regido da preposição $d e$, serve de complemento nominal a adjetivos; d) pertence a uma locução verbal e não está distanciado de seu auxiliar; e) depende de auxiliares causativos ou sensitivos e vem imediatamente depois desses verbos (CUNHA \& CINTRA, op.cit., p.474-6; ROCHA LIMA, op.cit., p.380-2). O emprego do infinitivo pessoal flexionado é tido como obrigatório quando tem sujeito próprio, diferente do sujeito da oração principal (ROCHA LIMA, op.cit.). Como casos de dupla construção são considerados os contextos em que: a) o infinitivo estiver afastado de seu auxiliar; b) o sujeito do infinitivo for um substantivo que serve ao mesmo tempo de complemento de ver, ouvir, deixar, fazer, mandar; c) se desejar pôr em evidência o agente da ação (op.cit. p.383-4).

Já Perini propõe uma análise descritiva que prevê as ocorrências de infinitivo flexionado dependentes de traços semânticos e sintáticos do verbo principal. Os verbos são divididos em três categorias: a primeira inclui basicamente verbos factivos, com os quais é livre a ocorrência de sufixo número-pessoal (Ex.: Os diretores lamentam profundamente não dispor(em) de recursos); a segunda abrange verbos (como querer) que têm subjuntivo no complemento, caso em que o sufixo número-pessoal é admitido se não houver correferencialidade de sujeitos 96 
(Ex.: O chefe quer que fiquemos até as oito.), ou que têm o infinitivo introduzido por preposição (Ex.: Nós queremos um visto para entrar(mos) no país); e a terceira compreende os demais verbos, sendo admitida a flexão número-pessoal se o infinitivo for introduzido por preposição ou se houver um candidato possível a sujeito da subordinada, especialmente em casos de "flutuação" (Ex.: Eles viram o desastre sem fazer(em) nada. Vi os cavalos correr(em)). (op.cit., p.201-6)

Todos os autores acima mencionados prevêem possibilidades de dupla construção no uso do infinitivo pessoal/impessoal. Camara Jr. chega a apontar que "para a estrutura atual da língua, o problema é saber até que ponto os dois infinitivos têm distribuição complementar ou se trata de variação livre" (op.cit., p.140). É justamente a variação no emprego do infinitivo pessoal na linguagem falada que se constitui no objeto deste estudo, em que se pretende, numa perspectiva da Teoria da Variação, descrever os contextos lingüísticos de (im)pessoalização do infinitivo no falar de Florianópolis. Considerando-se o caráter controvertido que cerca o fenômeno e admitindo-se que a pessoalização pode se dar via flexão verbal ou expressão do sujeito, as questões que orientam a discussão são as seguintes: a) em que medida os falantes utilizam o infinitivo pessoal? b) quais os contextos favorecedores e inibidores do uso de infinitivo flexionado e de infinitivo com sujeito expresso? ${ }^{1}$

A hipótese geral é que haja na fala uma forte inclinação à regularização da forma não flexionada de infinitivo, aliada ao não preenchimento do sujeito, esperando-se um comportamento mais enrijecido do infinitivo como impessoal. Esta hipótese se justifica, por um lado, pela tendência apontada em inúmeros trabalhos de redução do paradigma flexional associada a modificações ocorridas no paradigma pronominal (com a introdução de você e a gente e conseqüente diminuição no uso de $t u$ e nós, aliada ainda à perda de vós $)^{2}$; por outro lado, pela própria natureza do infinitivo: como 'forma nominal', assemelha-se menos a um verbo e mais a um substantivo denotativo de ação/estado, sem exprimir tempo nem modo, e, possivelmente, nem número, nem pessoa, valendo mais pela significação contida no próprio item lexical do que pela identificação de um eventual sujeito. Neste sentido, se caracterizaria por uma tendência à indeterminação semântica do sujeito.

\section{METODOLOGIA}

Foram levantados dados de 24 informantes florianopolitanos, estratificados por sexo, idade ( 25 a 49 anos e acima de 50 anos) e escolaridade (primário, ginasial e colegial). As entrevistas fazem parte do banco de dados do Projeto VARSUL (Variação Lingüística Urbana na Região Sul).

\footnotetext{
${ }^{1}$ Neste último caso, não como alternativas mutuamente excludentes.

${ }^{2}$ Vejam-se, por exemplo, Menon (1996a, 1996b), Duarte (1995, 1996), Monteiro (1994, 1996), Galves (1993), Paredes da Silva (1988).
} 
Foram analisadas construções com infinitivo que pudessem aceitar tanto flexão número-pessoal como sujeito expresso. Não foram consideradas na análise ocorrências dos seguintes tipos: a) locuções verbais, correferenciais e fortemente integradas; b) locuções com material interveniente (podia o onibus entrar; ia embora pra São Paulo trabalhar); c) infinitivos substantivados (brincando de esconder); d) outras construções fortemente integradas (quem tinha coragem de ir?).

Para testar a flexão do infinitivo e a expressão do sujeito, foram controladas as seguintes variáveis lingüísticas: correferencialidade, pessoa e forma do sujeito, (in)determinação do sujeito e estatuto sintático da oração com infinitivo; e sociais: sexo, idade e escolaridade. Os dados foram submetidos a tratamento estatístico através do pacote VARBRUL (PINTZUK, 1988) para cálculos de freqüências, percentuais e pesos relativos. Neste artigo, a ênfase recai sobre as variáveis lingüísticas.

\section{APRESENTAÇÃO E DISCUSSÃO DOS RESULTADOS}

\section{Flexão de infinitivo}

Inicialmente apresento de forma sucinta os resultados obtidos para a variável flexão do infinitivo. ${ }^{3}$ Entre os 1.429 dados de infinitivo coletados e analisados, foram encontradas 238 construções $(16 \%)$ potencialmente sujeitas à flexão, cujo sujeito pode ser identificado como tu (P2), nós (P4) ou eles/SN plural (P6), conforme exemplificado:

(01) Antigamente, pra tu ires pro aeroporto era uma viagem (FLP 24, L

(02) Atualmente é muito difícil nós sairmos (FLP 11, L 584)

(03) O governo admite eles venderem os imóveis à pessoa... (FLP 21, L

(04) Hoje eu fico muito decepcionada quando eu vejo políticos falarem do menor abandonado (FLP 15, L 398)

O percentual obtido para flexão de infinitivo nessas construções foi de apenas 8\% (19 ocorrências assim distribuídas: 03 para P2, 05 para P4 e 11 para P6). O fator lingüístico que se mostrou condicionante para esta variável foi presença formal do sujeito diante de infinitivo, com o seguinte comportamento: presença do sujeito favorece a flexão do infinitivo (peso relativo de 0,86 ) e ausência inibe esta marcação morfológica (peso relativo de 0,29). Portanto, a flexão coocorre com sujeito expresso, contrariando a hipótese funcional relativa à

\footnotetext{
${ }^{3}$ Retomo aqui parte do que foi exposto no $3^{\circ}$ Seminário do GT de Sociolingüística da ANPOLL, realizado em setembro/97 na UFPR. 98
} 
redundância informacional. Como infinitivos dessa natureza aparecem duplamente pessoalizados, podem ser considerados construções marcadas em português. Quanto a fatores sociais, os indivíduos que mais flexionam o infinitivo são os mais velhos $(0,66)$ e com grau de escolaridade mais alta $(0,70)$, resultados que podem ser respectivamente tomados como indicativos de mudança em progresso e da influência da escola na utilização do padrão normativo.

Passo, a seguir, a apresentar os resultados para a variável expressão do sujeito.

\section{Expressão do sujeito de infinitivo}

São discutidos aqui os grupos de fatores lingüísticos estatisticamente significativos em relação à variável em pauta, selecionados na seguinte ordem: correferencialidade do sujeito, (in)determinação semântica e estatuto sintático da oração. Em acréscimo detalham-se ainda resultados relativos a pessoa e forma do sujeito de infinitivo. ${ }^{4}$

\section{Correferencialidade e pessoa do sujeito}

Minha expectativa quanto à variável correferencialidade apóia-se, de um lado, na hipótese funcional sobre a (des)continuidade do tópico referencial (e na própria normatização gramatical que prevê o uso do infinitivo pessoal quando tem sujeito próprio, diferente do sujeito da oração principal) e, de outro lado, na hipótese geral relativa à regularização do infinitivo - donde se espera uma taxa reduzida de sujeito expresso, porém condicionada pela não correferencialidade. Os resultados encontram-se na Fig.1.

Influência da correferencialidade sobre a expressão do sujeito de INF na fala de Florianópolis (VARSUL)

\begin{tabular}{|c|c|c|c|}
\hline & \multicolumn{3}{|c|}{ Sujeito expresso } \\
\hline & Apl./Total & $\%$ & PR \\
\hline Não correferencial & $365 / 679$ & 54 & 0,83 \\
\hline Correferencial & $51 / 750$ & 07 & 0,19 \\
\hline Total & $416 / 1.429$ & 29 & \\
\hline
\end{tabular}

Fig.1

Observa-se que os dados analisados distribuem-se de modo equilibrado entre os dois fatores. O resultado que mais se destaca na tabela da Fig.1 diz respeito à taxa de representação formal de sujeito com infinitivo: $29 \%$ de sujeito

\footnotetext{
${ }^{4}$ A variável social sexo também se mostrou estatisticamente significativa para o fenômeno em estudo, com as mulheres preenchendo mais o sujeito de infinitivo $(0,57)$ do que os homens $(0,43)$ - resultados compatíveis com os de Duarte (1995), que analisou dados do Projeto NURC do Rio de Janeiro, e com os de Monteiro (1994), cuja amostra inclui dados das cinco capitais que integram o referido Projeto. As variáveis sociais, entretanto, não serão discutidas neste trabalho.
} 
expresso em oposição a $71 \%$ de não expresso. ${ }^{5}$ Este resultado é exatamente o oposto do que tem sido encontrado para preenchimento do sujeito com outros tempos verbais ${ }^{6}$, evidenciando-se, ao que parece, a tendência à regularização do infinitivo como impessoal.

Uma leitura vertical da tabela indica que, dos 416 casos de sujeito expresso, em $365(88 \%)$ não há correferencialidade (por outro lado, dos 1.013 sujeitos não expressos, em 699 (69\%) há correferencialidade), conforme o esperado. Numa leitura horizontal, percebe-se uma forte polarização na distribuição dos dados correferenciais, com $7 \%$ de preenchimento (e $93 \%$ de não preenchimento) e uma tendência bastante forte à inibição da expressão do sujeito correferencial $(0,19)$. Já a distribuição dos dados não correferenciais é mais equilibrada, com $54 \%$ de sujeitos expressos (e $46 \%$ de omitidos), embora o peso relativo associado seja bem diferenciado, com forte inclinação à expressão do sujeito não correferencial $(0,83)$. Tais resultados probabilísticos são compatíveis com a hipótese funcional segundo a qual a mudança de referente implica representação formal do mesmo e, em contrapartida, a continuidade do tópico referencial leva ao apagamento da marca do referente. Por outro lado, a relativa simetria dos resultados de freqüência para não correferencialidade não corresponde inteiramente à hipótese apontada acima, podendo ser interpretada como indício de regularização do infinitivo como impessoal. $O$ falante nem sempre sente necessidade de representar explicitamente o sujeito de infinitivo em contextos que seriam altamente favorecedores de sua expressão, ou seja, quando há mudança de referência, já que em praticamente metade das ocorrências desse tipo não se dá o preenchimento. Isso fica evidente nos exemplos abaixo, em que a ênfase está nos processos envolvidos e não na possível identificação de um agente (esta questão será retomada na seção seguinte):

(5) Minha mãe (...) ela achava o cúmulo ler aquilo ali né? (FLP 01, L176)

(6) Pra ela, ele mandou fazer um panelão de arroz (FLP 01, L481)

(7) Eu vou pedir pra trazer um cafezinho pra gente (FLP 01, L581)

(8) Isso era sinônimo de abrir a porta de voar em cima (FLP 01, L1331)

(9) (...) mil quilos de couve-flor. De cabeça, né? Ser limpa, lavada, passada na água de vinagre, pra depois ir no panelão pra cozinhar, depois tirar pra escorrer, pra preparar a salada (FLP 07, L456)

A seguir, detalham-se os resultados da Fig. 1, com especificação das pessoas do discurso.

\footnotetext{
${ }^{5}$ O papel inibidor do infinitivo sobre a presença de sujeito foi também constatado por Monteiro (1996) em análise do corpus Português Oral Culto de Fortaleza. O autor registra os seguintes resultados para presença de pronome: com infinitivo $(0,27)$, com subjuntivo $(0,75)$ e com indicativo $(0,50)$.

${ }^{6}$ Com relação à representação do sujeito, tem-se observado uma nítida preferência pelo preenchimento do sujeito no português falado no Brasil, em torno de 60 a $70 \%$, conforme atestam os trabalhos de Lira (1982); Monteiro (1994); Duarte (1995); Menon (1996a); Bonorino (1997); Seara (1997); entre outros. 100
} 
Cruzamento entre pessoa e correferencialidade para expressão do sujeito na fala de Florianópolis (VARSUL)

\begin{tabular}{|c|c|c|c|c|c|c|}
\hline & \multicolumn{2}{|c|}{ Suj. correfer. (expresso) } & Suj. não correfer. (expresso) & \multicolumn{2}{c|}{ Total } \\
\hline & freq. & $\%$ & freq. & $\%$ & freq & $\%$ \\
\hline P1 & $16 / 227$ & 7 & $47 / 80$ & 59 & $63 / 307$ & 21 \\
\hline P2 & $04 / 48$ & 8 & $23 / 23$ & 100 & $27 / 71$ & 38 \\
\hline P3 & $17 / 236$ & 7 & $172 / 236$ & 73 & $189 / 472$ & 40 \\
\hline P4 & $12 / 128$ & 9 & $83 / 87$ & 95 & $95 / 215$ & 44 \\
\hline P6 & $02 / 76$ & 3 & $40 / 69$ & 58 & $42 / 145$ & 30 \\
\hline Total & $51 / 715$ & 7 & $365 / 495$ & 74 & $416 / 1.210$ & 34 \\
\hline
\end{tabular}

Em termos de freqüência total bruta, os sujeitos mais preenchidos são P3 ( 189 ocorrências $=45 \%$ do total dos sujeitos expressos), P4 (95 ocorrências $=23 \%$ do total) e P1 ( 63 ocorrências $=15 \%$ do total); a pessoa menos preenchida é P2 (27 ocorrências $=7 \%$ dos preenchimentos). Em termos percentuais que comparam expressão e omissão do sujeito por pessoa, o sujeito que menos aparece é P6 (seja correferencial (3\%) ou não correferencial (58\%)) e os que mais aparecem são P2 ( $8 \%$ para correferencial e $100 \%$ para não correferencial) e $\mathrm{P} 4(9 \%$ e $95 \%$, respectivamente). Os números indicam que ser ou não correferencial parece afetar do mesmo modo a expressão do sujeito em todas as pessoas. Ou seja, os percentuais mais altos e mais baixos associam-se à mesma pessoa, o que muda é a freqüência de ocorrências, que é bem maior na expressão de sujeitos não correferenciais.

Cada uma das pessoas do discurso é codificada por formas diferenciadas, como se vê abaixo.

Distribuição das formas de sujeito de INF expresso por pessoa do discurso na fala de Florianópolis (VARSUL)

\begin{tabular}{|c|c|c|c|c|c|c|c|c|c|c|}
\hline \multicolumn{2}{|l|}{ P1 } & \multicolumn{2}{|l|}{ P2 } & \multicolumn{2}{|l|}{ P3 } & \multicolumn{2}{|l|}{ P4 } & \multicolumn{2}{|l|}{ P6 } & \multirow[t]{2}{*}{ Total } \\
\hline Eu: & 34 & Tu: & 16 & Ele: & 71 & Nós: & 18 & Eles: & 23 & \\
\hline Mim: & 29 & Ti: & 02 & SN: & 104 & A gente: & 77 & SN: & 19 & \\
\hline \multirow{2}{*}{\multicolumn{2}{|c|}{ Total - 63}} & Você: & 09 & Se: & 14 & & & & & \\
\hline & & \multicolumn{2}{|c|}{27} & \multicolumn{2}{|c|}{189} & \multicolumn{2}{|l|}{95} & \multicolumn{2}{|c|}{42} & 416 \\
\hline
\end{tabular}

Observe-se que em P2 há predomínio de tulti (67\%) sobre você $(33 \%)$ e em P4 há predomínio de a gente (81\%) sobre nós (19\%) como sujeitos de infinitivo ${ }^{8}$. A forma mais recorrente é a de SN pleno em terceira pessoa do singular

\footnotetext{
${ }^{7}$ Foram excluídas desta tabela 219 ocorrências, cuja pessoa e/ou referência não foi identificada, o que alterou sensivelmente o resultado percentual para expressão de sujeito não correferencial, relativamente à Fig.1.

${ }^{8}$ Esses resultados corroboram os obtidos por Bonorino (1997), que encontrou 73\% de ocorrências de $t u$ em oposição a $27 \%$ para você na função de sujeito; e os de Seara (1997), que apontam uma taxa de $70 \%$ para a gente e $30 \%$ para nós nos dados de Florianópolis (VARSUL), considerando-se todos os tempos verbais.
} 
(correspondendo a um quarto do total de sujeitos expressos). Observe-se ainda que você (09 ocorrências) aparece menos que se (14 ocorrências). Vale destacar os casos em que as formas oblíquas são usadas como sujeito: no caso de mim, a concorrência com eu é bastante acentuada (46\% e 54\%, respectivamente); já $t i$ é bem menos freqüente que tu (11\% e 89\%, respectivamente). Por ordem de freqüência de ocorrências temos a seguinte distribuição, considerando-se a forma e o percentual:

Forma: $\quad \mathrm{SN}(\mathrm{P} 3)>$ a gente $>$ ele $>$ eu $>$ mim $>$ eles $>\mathrm{SN}(\mathrm{P} 6)>$ tu, nós, $^{9} \mathrm{se}^{9}>$ você $>$ ti

$\begin{array}{llllllllllll}\%: & 24 & 19 & 17 & 8 & 7 & 5,5 & 4,5 & 4 & . . & 2,5 & 0,5\end{array}$

Exemplos:

(10) Hoje já é mais difícil uma mãe permitir que o filho fume (FLP 04,

(11) Eu acho que está muito mais fácil pra gente viver agora (FLP 12,

(12) Tirava a cadeira do funcionário pra ele cair no chão (FLP 12, L527)

(13) Antes, sem eu saber, ele mandou uma carta pro chefe (FLP 12, 535)

(14) Hoje, graças a Deus, já está uma vida bem mais fácil pra mim viver com ela (FLP 07, L54)

(15) A gente naquela agitação (...) pra eles não poder se machucar (FLP

(16) Apesar dos pais chamar a atenção e tudo, a gente ia (FLP 18, L564)

(17) É difícil tu, como mãe, aceitares uma coisa dessa, né? (FLP 11,

(18) Ele nos deu a carta pra todos nós ler (FLP 12, L554)

(19) Eu lecionei pra terceiro ano, uma classe bem melhor de se trabalhar (FLP 12, L1230)

(20) Antes de você fazer alguma coisa, você vem (...) (FLP 13, L972)

(21) Dez reguadas pra ti aprender a ficar quieto quando eu mando (FLP 18, L394)

Resumindo os principais resultados mostrados nesta seção, pode-se dizer que existe uma forte tendência para a inibição da expressão formal do sujeito de infinitivo quando há correferencialidade $(0,19)$ e para o preenchimento quando os sujeitos são não correferenciais $(0,83)$. Deve-se levar em conta, entretanto, que a polarização constatada na distribuição de freqüências para sujeito correferencial não expresso (93\%) e expresso $(07 \%)$ não se verifica de igual modo para sujeito não correferencial (46\% de sujeito não expresso e 54\% de sujeito expresso) - fato que pode ser interpretado como indício de regularização do infinitivo como

\footnotetext{
${ }^{9}$ Cada um dos três pronomes com $4 \%$ de ocorrências.
} 
impessoal (já que a expressão do sujeito devido à mudança de referente não se realiza com a intensidade inicialmente prevista). Verificou-se ainda que parece não haver restrição de pessoa relativamente ao preenchimento ou não do sujeito seja ele correferencial ou não correferencial. Por fim, foram observadas algumas particularidades quanto à forma pronominal utilizada para expressar o sujeito: alta variabilidade entre $\operatorname{mim}(46 \%)$ e eu $(54 \%)$ para referir P1; franca preferência pelo emprego de tu $(60 \%)$ sobre você $(33 \%)$ e $t i(07 \%)$ para designar P2; uso de se $(07 \%)$ concorrendo com ele $(a)(38 \%)$ e com SN pleno para referir P3; predomínio de a gente (81\%) sobre nós (19\%) para indicar P4.

\section{(In) determinação semântica}

Foram considerados casos de indeterminação ${ }^{10}$ semântica do sujeito aqueles em que não se pode precisar o referente, podendo o mesmo designar uma massa humana indiferenciada (o pessoal, todo mundo), participante(s) não relacionado(s) a circunstâncias definidas (o cara, a pessoa, você, a gente), podendo o falante estar ou não incluído no grupo (ver exemplos (22)-(28) abaixo). Por outro lado, o sujeito é determinado quando é possível definir ou precisar seu referente no discurso, ou seja, quando se pode identificá-lo.

Esta variável foi a segunda estatisticamente significativa no condicionamento da expressão do sujeito de infinitivo. Os resultados mostram uma correlação acentuada entre determinação e expressão do sujeito e entre indeterminação e não preenchimento do sujeito, conforme o previsto.

(In)determinação e expressão do sujeito de INF na fala de Florianópolis

\begin{tabular}{|c|c|c|c|}
\hline & \multicolumn{3}{|c|}{ Sujeito expresso } \\
\hline & Apl./Total & $\%$ & PR \\
\hline Indeterminado & $159 / 696$ & 23 & 0,33 \\
\hline Determinado & $257 / 733$ & 35 & 0,66 \\
\hline Total & $416 / 1.429$ & 29 & \\
\hline
\end{tabular}

Fig. 4

$\mathrm{Na}$ sua totalidade, os dados distribuem-se de modo equilibrado entre os dois fatores, com $49 \%$ de indeterminação e $51 \%$ de determinação semântica do sujeito. Dos 416 dados de sujeito expresso, 257 (62\%) são semanticamente determinados (já no caso dos não preenchidos, há 537 ocorrências (53\%) de indeterminação semântica). Os pesos relativos acentuam a correlação significativa

\footnotetext{
${ }^{10}$ Para a noção de indeterminação, tomo por base Almeida (1991), para quem o sujeito indeterminado é referencialmente específico (i.e., inscreve sua referência num conjunto relativo a uma espécie ou classe) de modo impreciso (referindo-se a uma parte não determinada da espécie ou classe representada). A indeterminação é tratada como fenômeno escalar e a referencialidade como instaurada discursivamente.
} 
entre determinação e expressão do sujeito $(0,66)$ e entre indeterminação e não expressão do sujeito $(0,67)^{11}$.

Nos casos de sujeito expresso indeterminado, são comuns os sintagmas nominais o pessoal, o cara, a pessoa, todo mundo, bem como os pronomes indefinidos nada, ninguém, todos, alguém, além do emprego de a gente e tu/você indeterminados. A pessoa menos sujeita à indeterminação é P1. Exemplos:

(22) Eles tinham matadouro e ali ficava fechado pra esse dia, um boi, dois, três pra botar na vara naquele dia pro pessoal brincar. (FLP 07, L272)

(23) A não ser que chovesse mesmo porque aí era obrigado todo mundo sair (FLP 24, L722)

(24) Não votar em ninguém porque (...) não vale a pena a pessoa arriscar um voto de confiança (FLP 14, L594)

(25) Eles liberavam pro cara pegar (FLP 19, L172)

(26) Eu não vejo ninguém falar contra ele (FLP 19, L689) 04, L939)

(27) Até é chato a gente dizer muitas vezes que a gente foi honesto (FLP

(28) Com um diploma na mão é mais fácil você se ajeitar, pegar um serviço (FLP 02, L1311)

Comparem-se os exemplos abaixo, considerando a questão da (im)pessoalidade e da indeterminação:

(29) Acho que é muito feio a pessoa ser desonesta (FLP 04, L944)

(30) Punir as pessoas na frente dos outros é feio (FLP 04, L1097)

Em ambas as frases temos infinitivo em oração subordinada subjetiva, sendo que apenas na primeira há sujeito preenchido para INF. Entretanto, a expressão do sujeito nada acrescenta em termos semânticos, persistindo a indeterminação em (29) e (30).

Por outro lado, em muitos casos considerados como tendo sujeito determinado não expresso, passível de ser identificado no contexto lingüístico, a não realização do sujeito diante do infinitivo coloca em tal evidência a ação, deixando em plano de fundo o agente, que os referentes parecem receber um certo matiz de indeterminação. Com tal estratégia, conforme se observa nos exemplos (31) - (37) abaixo, o sujeito parece se situar a meio caminho entre a determinação e a indeterminação semântica ${ }^{12}$.

(31) A das seis também não tem como contar porque eu agora não assisto (FLP 09, L388)

\footnotetext{
${ }^{11}$ Resultado obtido ao se tomar a não expressão do sujeito como referência.

12 É como se tratássemos a (in)determinação como um continuum, cujas extremidades são claramente definidas perdendo os elementos sensivelmente a nitidez e apresentando uma certa sobreposição ao se situarem em posição intermediária na escala.

104
} 
(32) Me convidaram pra trabalhar no Clube Doze de Agosto (FLP 13,

(33) Eu gostava muito assim de esticar a perna, né? pra ver se encostava lá no meu irmão, na minha irmã, assim, pra ver gritar (FLP 15, L681)

(34) (programa) aquele, o Valter Filho só, é de manhã cedo. Até umas oito horas, até a hora de sair pro serviço, depois não tenho mais tempo de ouvir rádio (FLP 17, L114)

(35) (ela) ela ficou internada e foi necessário tomar sangue (FLP 14, L469)

(36) Eu gosto daqui (...) outro lugar pra passear, sim, fosse pra passear, sim, mas pra nascer em outro lugar(...), não. Eu gosto daqui (FLP 17, L1069)

(37) Uma das coisas que eu sempre gostei na vida foi de participar do futebol. Não só participar diretamente como assistir também (FLP 21, L216)

Finalizando esta seção, pode-se dizer que, no geral, sujeitos semanticamente determinados inclinam-se a ser expressos $(0,66)$, enquanto sujeitos semanticamente indeterminados inibem a expressão $(0,33)$. Em acréscimo, formula-se a hipótese que o não preenchimento de sujeitos identificáveis no discurso, a par de colocar em realce a situação codificada pelo verbo, pode ser uma estratégia discursiva de atribuir ao sujeito uma certa indeterminação ${ }^{13}$.

\section{Estatuto sintático da oração}

Com o controle desta variável objetiva-se caracterizar os contextos sintáticos que favorecem e inibem a expressão do sujeito de infinitivo. Em termos gerais, a expectativa inicial era de que as construções com verbos causativos trariam mais sujeito expresso em decorrência do traço semântico associado a verbos manipulativos ${ }^{14}$ desse grupo. Também em virtude de características semânticas relativas à não correferencialidade presente na grande maioria das subordinadas substantivas, esperava-se maior realização do sujeito de infinitivo neste contexto. As adverbiais, em sua grande maioria com correferencialidade, apresentariam menos sujeito expresso.

A figura abaixo traz alguns fatores amalgamados por terem mostrado um comportamento mais ou menos homogêneo entre si: as construções cujo verbo principal apresenta complemento que funciona também como sujeito de infinitivo e as orações subjetivas, por serem os fatores que apresentam maior taxa de preenchimento de sujeito e maior peso relativo associado; as orações substantivas objetivas diretas e indiretas; as completivas nominais foram amalgamadas com as

${ }^{13} \mathrm{Ou}$, pelo menos, de reduzir seu grau de determinação semântica.

${ }^{14}$ Verbos manipulativos indicam, em termos gerais, manipulação ou desejo de manipulação por um agente (sujeito da oração principal) de outro agente potencial (objeto da principal e sujeito da oração complemento reduzida de infinitivo) (GIVÓN, 1990). 
adverbiais, pois ambas inibem igualmente a expressão do sujeito de infinitivo. Vejam-se os resultados obtidos:

Influência do estatuto sintático da oração sobre a expressão do sujeito de INF na fala de Florianópolis

\begin{tabular}{|c|c|c|c|}
\hline & Apl./Total & $\%$ & PR \\
\hline V (OD/OI=suj) V/SUBJ & $133 / 186$ & 72 & 0,86 \\
\hline Coordenada & $15 / 45$ & 33 & 0,72 \\
\hline OI/OD & $29 / 73$ & 40 & 0,63 \\
\hline Pred. & $11 / 45$ & 24 & 0,55 \\
\hline Dar pra -R & $14 / 41$ & 34 & 0,49 \\
\hline Adv/CN & $214 / 1.034$ & 21 & 0,40 \\
\hline Total & $416 / 1.424$ & 29 & \\
\hline
\end{tabular}

Fig.5

Exemplificando os diferentes fatores:

$\mathrm{OD}=$ suj (38) Se você deixar a pessoa querer que você ande... (FLP 02. L637)

$\mathrm{OI}=$ suj (39) Pediram pra mãe dar uma olhadinha (FLP 03, L637)

Subj. (40) Atualmente é muito difícil nós sairmos (FLP 11, L584)

Coord. (41) Não dou um passo antes de ir pra comprar as coisas e ficar devendo (FLP 13, L1009)

OI (42) Hoje eu me arrependo de não ter eu ido contar pra ele ... (FLP 20,

889)

OD (43) Não tenho como comprar um terreno (FLP 09, L496)

Pred. (44) Meus planos é ir pra casa (FLP 07, L563)

Dar pra-R (45) Na época dava pra comprar brinquedo, né? (FLP 09, L25)

Adv. (46) Ele está aguardando o próximo vestibular pra ver se passa (FLP 02, L54)

CN (47) Quando começa a tomar um refrigerante, dá vontade de fumar um cigarrinho

(FLP 04, L443)

Os resultados apontam para os seguintes contextos favorecedores do preenchimento: construções com verbos causativos ou de percepção e oração subjetiva $(0,86)$ - contextos em que se concentra a taxa maior de expressão do sujeito $(72 \%)-\mathrm{e}$ oração objetiva (in)direta $(0,63)$. Como contextos desfavorecedores ao preenchimento do sujeito temos oração adverbial e completiva nominal $(0,40)$, com a taxa mais baixa de preenchimento $(21 \%)$. As construções do tipo dar pra - $R(0,49)$ e as predicativas $(0,55)$ apresentam um comportamento mais neutro, embora o percentual de sujeito expresso associado a estas últimas seja bastante baixo $(24 \%)$. Quanto às coordenadas, o resultado que mostra alto peso relativo associado a um baixo percentual fica comprometido pelo desvio ocasionado pela interferência de outros fatores, especialmente da correferencialidade.

106 
Observando-se nos dados as diferentes construções reunidas no primeiro fator da Fig. 5 - segundo tipo mais recorrente em termos de freqüência -, verificase que cerca de um quarto dos enunciados é de orações subjetivas (72 ocorrências); os demais distribuem-se em dois grupos, o primeiro constituído por verbos transitivos diretos ( 88 ocorrências) e o segundo por verbos bi-transitivos ou transitivos indiretos (26 ocorrências). Vejam-se outros exemplos do primeiro grupo: 01, L520)

(48) Ele comprou dois cachos de bananas e fez ela comer todinha (FLP

(= fez com que ela comesse - OD)

(= $a$ fez comer)

(49) Deixa eu terminar (FLP 16, L1021)

(= deixa que eu termine - OD)

(=me deixa(-me) terminar)

(50) Elas viram eu tomar aquilo (FLP 20, L1031)

(= viram que eu tomei - OD)

(=me viram(-me) tomar)

Os três exemplos trazem pronome reto ocupando o lugar do oblíquo, como indicativo formal da função de sujeito e posição de objeto. Os verbos principais desse grupo são, como já mencionado, causativos e sensitivos. Os primeiros distribuem-se num continuum que vai de um grau maior de controle do agente da oração principal sobre o agente potencial da subordinada com manipulação bem sucedida, até um grau menor de controle, havendo sempre interferência do agente da oração matriz, conforme encontramos em nossos dados: forçar a, fazer, pôr/botar a, deixar, ajudar a-de um extremo de obrigação, mais acentuada a menos acentuada, passando por permissão e chegando à cooperação, na relação entre os sujeitos. Todos os causativos, com exceção de mandar, mostram-se como contextos altamente favorecedores da expressão do sujeito de infinitivo. O verbo mandar é o único deste grupo a apresentar um comportamento radicalmente oposto, restringindo a representação formal do sujeito e aparecendo conforme ilustrado abaixo, na grande maioria das construções analisadas:

(51) Um pedaço de carne (...) que eu mandava buscar (FLP 06, L894)

(52) Ele mandou fazer um panelão de arroz (FLP 01, L481)

Com os verbos sensitivos (ver, ouvir), embora em menor grau que com os verbos causativos, também há envolvimento do sujeito da oração principal com a situação codificada na subordinada, posto que o sujeito da primeira é o experienciador da situação representada na oração com infinitivo, conforme exemplo (50). Na maioria das ocorrências, tanto de verbos causativos como de percepção, há traço de agentividade no sujeito de infinitivo, o que, somado à nãocorreferencialidade e ao tipo de envolvimento dos dois sujeitos, caracteriza o contexto mais propício à representação formal do sujeito de infinitivo. 
Como exemplos do segundo grupo (objeto indireto $=$ sujeito), vejam-se: L995)

(53) Nós pedíamos [pra ele] confeccionar (...) duas rodinhas (FLP 02,

(= pedíamos (a ele) que ele confeccionasse - OD)

(54) As enfermeiras deram um quarto lá [prá nós] dormir (FLP 03, L901)

(= deram (a nós) um quarto para que nós dormíssemos - ADV)

(55) Telefonaram [pra mim] vir urgente em casa (FLP 05, L334)

(= telefonaram (a mim) para que eu viesse... - ADV)

Nas frases acima, o SN/pronome do complemento preposicionado parece funcionar simultaneamente como objeto indireto do verbo principal e sujeito de infinitivo em orações reduzidas objetivas diretas ou adverbiais, já que correferenciais. A preposição pra normalmente introduz objeto indireto dos verbos pedir/dar/telefonar; os enunciados, entretanto, apresentam na seqüência um verbo no infinitivo que tem como sujeito o pronome que o antecede. Daí a dupla função atribuída ao nominal do sintagma preposicionado. Em casos como esses, é quase que categórica a expressão do sujeito nos dados analisados. Observe-se que grande parte dos verbos desse grupo são também manipulativos em algum grau, como em (53) e (55).

Voltando à hipótese inicial a respeito do estatuto sintático da oração, vê-se confirmada nossa expectativa relativa ao primeiro fator da tabela, no que concerne a verbos manipulativos e de percepção, com a ressalva de que, dentre esses, mandar parece estar a caminho de um enrijecimento adquirindo características de auxiliar em termos de integração sintática com o infinitivo que o segue.

Ainda detalhando a Fig. 5, verifica-se que os tipos de oração com infinitivo mais recorrentes nos dados são a adverbial ( $871=61 \%$ do total de dados) e a completiva nominal (163 dados); são também as que apresentam o percentual mais baixo de preenchimento do sujeito (21\%). As adverbiais constituem o conjunto que apresenta maior diversidade de graus de integração sintáticosemântica entre seus elementos. Vejam-se os exemplos, todos com correferencialidade entre os sujeitos do verbo principal e do infinitivo, dispostos numa hierarquia de integração:

(56) A gente esperava que o vizinho comesse esse negócio todo aí pra gente poder ganhar alguma coisa (FLP 18, L299)

(57) $\mathrm{Na}$ hora do recreio a gente ia tudo pro muro que tinha assim no Instituto pra ver o negócio de hasteamento da bandeira (FLP 18, L478)

(58) Ele queria vender a passagem, inclusive, pra comprar uma casa (FLP 09, L544)

(59) A mãe ia lá pra casinha pra limpar a nossa cabeça (FLP 09, L22)

(60) Eles vieram pra trabalhar (FLP 08, L83)

Os dois primeiros enunciados são estruturalmente mais complexos, trazendo uma oração subordinada intercalada entre o verbo principal e o infinitivo, 
este com sujeito expresso em (56) e em (57) não. Observe-se que no primeiro caso há um concorrente a sujeito de infinitivo (o vizinho), daí para efeitos comunicativos ser necessário explicitar o sujeito (a gente). Já o segundo não apresenta tal risco de ambigüidade. $\mathrm{O}$ terceiro exemplo traz somente dois verbos com correferencialidade. Os dois últimos enunciados são mais integrados, ambos com verbo principal de movimento (ir/vir), em (59) com um locativo intercalado e em (60) sem locativo, mostrando esta última construção um grau máximo de integração em termos de oração adverbial, uma vez que a simples exclusão da preposição parece resultar numa locução em que o verbo principal passa a comportar-se como auxiliar (vieram trabalhar). Nos exemplos acima, o traço de correferencialidade dos sujeitos é o denominador comum que justifica a ausência formal de sujeito de infinitivo (exceto (56)). A série abaixo exibe não correferencialidade de sujeitos:

(61) Não tinha médico pra fazer o parto (FLP 08, L637)

(62) Vou arranjar uma mulher pra cuidar de tudo (FLP 08, L674)

(63) Vou levar a senhora pra senhora conhecer a terra (FLP 08, L 48)

(64) Ela fica com as minhas crianças pra gente ir... (FLP 09, L236)

(65) (A gente) vendia pluma de pato pra fazer cobertor (FLP 08, L327)

Nas três primeiras frases do conjunto acima, o objeto do verbo principal é correferencial ao sujeito de infinitivo (aparentemente lembrando a estrutura do primeiro fator da Fig. 5). Comparem-se:

(66) Pediram pra mãe dar uma olhadinha (FLP 03, L637)

(67) Vou arranjar uma mulher pra cuidar de tudo (FLP 08, L674)

Observe-se a redução: 'pediram pra mãe (pra mãe) dar uma olhadinha' / 'vou arranjar uma mulher pra (mulher) cuidar'). Não é usual preencher o sujeito como acontece em (63), uma vez que o referente seja facilmente recuperado no contexto precedente. Já em (64) a total ausência de correferencialidade leva a expressar o sujeito do infinitivo, cujo referente determinado ( $a$ gente $=$ os pais das crianças) não pode ser identificado se omitido, criando uma situação de ambigüidade. Embora (65) seja de tipo semelhante, o fato de haver indeterminação semântica do sujeito de infinitivo permite a não representação do mesmo sem risco para o entendimento do enunciado.

Junto das adverbiais, as completivas nominais, em sua maioria correferenciais, também atuam como inibidoras da expressão do sujeito. Vejam-se alguns dados:

(68) Eles estão ansiosos assim pra ter esse neném (FLP 20, L1213)

(69) A gente já tem pouca liberdade pra fazer o que quer (FLP 17, L1087)

(70) Eu acho que está na hora de parar até pra dar lugar pros mais jovens (FLP 21, L207)

(71) A Camila está naquela fase de engatinhar (FLP 20, L1262) 
(72) Aqui até que é um bairrozinho bom, sabe? de morar (...) é um lugarzinho bom de se morar 9FLP 15, L815) 18, L695)

(73) Antigamente o caminho pra ir pros Ingleses era mais pra dentro (FLP

Nesse tipo de construção, há em torno de $80 \%$ de não representação formal do sujeito, independentemente de ser ou não indeterminado. A justificativa para tal restrição parece residir na forte integração sintático-semântica existente entre o complemento e o nome que o antecede, fazendo com que as completivas nominais fiquem menos sujeitas à pessoalização do infinitivo.

A construção dar pra $-R$ foi controlada separadamente, embora contenha uma oração subjetiva, dado seu caráter de construção quase que cristalizada. $\mathrm{O}$ controle separado mostrou-se relevante, pois enquanto as subjetivas correlacionamse fortemente ao preenchimento do sujeito $(0,86)$, as do tipo dar pra $-R$ não favorecem o aparecimento do sujeito $(0,49)$. É um tipo específico de construção, tal como acontece com o verbo mandar, caracterizando-se ambos como restrição à expressão do sujeito.

$\mathrm{Na}$ categoria das substantivas, verifica-se que há um comportamento bem distinto entre os tipos: enquanto as subjetivas e as completivas de verbos causativos condicionam fortemente o aparecimento do sujeito $(0,86)$ bem como as demais completivas verbais, porém em menor intensidade $(0,63)$, as completivas nominais inibem a expressão do sujeito $(0,40)$, e as predicativas inclinam-se fracamente ao preenchimento $(0,55)$. Tem se proposto uma análise interpretativa de base sintático-semântica para esses resultados. Nesta perspectiva, observa-se, com relação às subjetivas e predicativas, que ambas compartilham o fato de serem predominantemente não correferenciais, mas comportam-se de maneira radicalmente oposta quanto à distribuição relativa ao preenchimento do sujeito, as primeiras com sujeito expresso em $76 \%$ das ocorrências e as últimas sem sujeito expresso em proporção aproximada. Observem-se alguns exemplos ilustrativos dos dados analisados:

(74) Ele disse que era bom nós levar ela pro hospital (FLP 03, L1216)

(75) Não adianta às vezes a pessoa viver na igreja (...) (FLP 15, L159)

(76) Naquele tempo era muito difícil a gente ver um abacate (FLP 12,

(77) Não vale a pena arriscar um voto de confiança (FLP 14, L594)

(78) A festa da tainha é de fazer aquelas bancas (FLP 07, L970)

(79) O dever da gente é o ano todo, toda Sexta não comer (FLP 07, L1044)

(80) O meu sonho era conseguir fazer a cirurgia no meu seio (FLP 20,

(81) O negócio não é só ser assaltado em si, mas é tirar os documentos novamente (FLP 19, L269) 
De (74) a (77) temos enunciados que se caracterizam por conter na principal uma opinião avaliativa sobre a situação descrita na oração subjetiva, esta normalmente trazendo sujeito expresso. De (78) a (81), os enunciados se particularizam pelo caráter atributivo, praticamente isento de referencialidade, presente na oração predicativa que funciona como atributo do sujeito da matriz. Assim, a própria configuração semântica de cada tipo parece motivar ou restringir a expressão do sujeito da subordinada. Espera-se menos referencialidade num constituinte atributivo e mais em situações factuais ou estados sobre os quais se tecem comentários avaliativos.

\section{CONSIDERAÇÕES FINAIS}

Retomando as questões gerais que orientam esta investigação, pode-se dizer que os falantes florianopolitanos utilizam muito pouco o infinitivo pessoal, flexionando o verbo em apenas $8 \%$ das ocorrências sujeitas à flexão e preenchendo o sujeito em $29 \%$ dos casos analisados, com tendência para marcar duplamente os casos de concordância, uma vez que a flexão é fortemente condicionada por sujeito expresso diante de infinitivo. Em termos gerais, como contextos favorecedores da pessoalização através da expressão do sujeito temos: sujeito não correferencial e determinado, construções de infinitivo como complemento de verbos causativos e sensitivos, orações subjetivas e completivas verbais. Os contextos propícios à impessoalização são: correferencialidade de sujeitos, indeterminação, orações adverbiais e completivas nominais; ainda como restrições à expressão do sujeito aparecem construções com verbo mandar e dar pra $-R$. Os resultados quantitativos e a análise qualitativa dos dados apontam para condicionamentos de natureza sintático-semântica.

A distribuição equilibrada entre a representação formal e a ausência do sujeito em dados não correferenciais (contexto geralmente tido como propício ao preenchimento do sujeito) é interpretada como um indício de regularização do infinitivo como impessoal - reforçando o que já é apontado pela baixa taxa de sujeito formalmente realizado no total dos dados analisados (conforme destacado no parágrafo anterior). No caso específico de sujeitos não correferenciais e semanticamente determinados, seu não preenchimento parece ser uma estratégia discursiva de atribuir realce à situação codificada pelo verbo e, inversamente, de restringir o caráter determinado do sujeito, atribuindo-lhe um matiz de indeterminação.

Através do controle do estatuto sintático da oração de infinitivo, verificouse que há também aspectos semântico-discursivos importantes envolvidos no condicionamento da variável em estudo. As construções com verbos causativos e sensitivos, que favorecem grandemente a expressão do sujeito, abarcam manipulação de um agente da principal sobre um objeto que é também agente potencial da subordinada; as orações subjetivas codificam situações que são alvo 
de comentários avaliativos do enunciador, favorecendo a expressão do sujeito, enquanto as predicativas envolvem valor atributivo, restringindo a referencialidade, e as completivas nominais apresentam um alto grau de vinculação sintáticosemântica entre o nome e seu complemento, dificultando a intercalação formal de um sujeito. As adverbiais, por sua vez, são tipicamente correferenciais, traço inibidor por excelência da representação do sujeito.

Com este estudo se pretendeu identificar e descrever os contextos lingüísticos favoráveis à (im)pessoalização do sujeito no português falado e interpretá-los segundo uma visão funcional da língua. Como desdobramentos da pesquisa, prevê-se uma análise criteriosa das variáveis sociais com ênfase no fenômeno de mudança em tempo aparente, bem como uma análise comparativa entre fala e escrita, para se avaliar em que medida o fenômeno está sujeito a restrições de modalidade ou canal.

\section{BIBLIOGRAFIA}

ALMEIDA, Maria Lúcia Leitão de. A indeterminação do sujeito no português falado. Rio de Janeiro, UFRJ, 1991. Tese de Doutorado.

BONORINO, Mercedes. A variável preenchimento do sujeito no falar de Florianópolis. Florianópolis, UFSC, 1997. Dissertação de Mestrado.

CAMARA JR., Joaquim Mattoso. História e estrutura da língua portuguesa. 4 ed. Rio de Janeiro, Padrão, 1985.

CUNHA Celso e CINTRA, Lindley. Nova gramática do português contemporâneo. 2 ed. Rio de Janeiro, Nova Fronteira, 1985.

DUARTE, Maria Eugênia. Do pronome nulo ao pronome pleno: a trajetória do sujeito no português do Brasil. In: ROBERTS, Ian e KATO, Mary (orgs.) Português brasileiro: uma viagem diacrônica. Campinas, Ed. da UNICAMP, 1993.

. A perda do princípio "evite pronome" no português brasileiro. Campinas, Unicamp, 1995. Tese de Doutorado.

. Aspectos do sistema pronominal do português falado nas regiões sudeste e centro-oeste. Mesa-redonda: Aspectos do sistema pronominal relevantes para o ensino básico. Anais do XI Encontro Nacional da ANPOLL, p. 504-9, 1996.

GALVES, Charlotte C. O enfraquecimento da concordância no português brasileiro. In: ROBERTS, Ian e KATO, Mary (orgs.), Português brasileiro: uma viagem diacrônica. Campinas, Ed. da UNICAMP, 1993.

GIVÓN, Talmy. Syntax - a functional-typological introduction, v. II. Philadelphia, J. Benjamins, 1990.

GORSKI, Edair. O Infinitivo na fala de Florianópolis: (im)pessoalização. Mesaredonda: Morfossintaxe do português do Brasil: variação e mudança. $3^{\circ}$ Seminário do GT de Sociolingüistica da ANPOLL. Curitiba, UFPR, set. 1997. 
LIRA, Solange A. Nominal, pronominal and zero subject in Brazilian portuguese. University of Pennsylvania, 1982. Tese de doutorado.

MENON, Odete. O sistema pronominal na região sul. Mesa-redonda: Aspectos do sistema pronominal relevantes para o ensino básico. Anais do XI Encontro Nacional da ANPOLL, p. 510-12, 1996.

- Uso dos pronomes sujeito de $1^{a}$ pessoa: uma análise sociolingüística. Curitiba, UFPR, 1996. Tese de Professor Titular.

MONTEIRO, José L Pronomes pessoais. Fortaleza, EUFC, 1994.

. O sistema pronominal na região nordeste. Mesa-redonda: Aspectos do sistema pronominal relevantes para o ensino básico. Anais do XI Encontro Nacional da ANPOLL, p. 513-15, 1996.

PAREDES da SILVA, Vera Lúcia. Cartas cariocas: a variação do sujeito na escrita informal. Rio de Janeiro, UFRJ, 1988. Tese do Doutorado.

PERINI, Mário A. Gramática descritiva do português. 2 ed. São Paulo, Ática, 1996.

PINTZUK, Suzan. VARBRUL programs. 1988.

ROBERTS, Ian e KATO, Mary (orgs.) Português Brasileiro: uma viagem diacrônica. Campinas, Ed. da UNICAMP, 1993.

ROCHA LIMA, Carlos Henrique da. Gramática normativa da língua portuguesa. 27 ed. Rio de Janeiro, J. Olympio, 1986.

SAID ALI, Manuel. Dificuldades da Língua Portuguesa . 3 ed. Rio, Livraria Francisco Alves, 1930.

. Gramática Secundária e Gramática Histórica da Língua Portuguesa. 3 ed. Brasília, Ed. Universidade de Brasília, 1964.

SEARA, Izabel C. Expressão variável do sujeito nós e a gente na fala de informantes florianopolitanos. Florianópolis, UFSC, 1997. Dissertação de Mestrado. 